\title{
BMJ Open Disaster anxiety and self-assistance behaviours among persons with cervical cord injury in Japan: a qualitative study
}

\author{
Kyo Takahashi, ${ }^{1,2}$ Yayoi Kitamura ${ }^{1}$
}

To cite: Takahashi $\mathrm{K}$, Kitamura Y. Disaster anxiety and self-assistance behaviours among persons with cervical cord injury in Japan: a qualitative study. BMJ Open 2016;6:e009929. 009929

- Prepublication history for this paper is available online. To view these files please visit the journal online (http://dx.doi.org/10.1136/ bmjopen-2015-009929).

Received 7 September 2015 Revised 18 February 2016 doi:10.1136/bmjopen-2015Accepted 31 March 2016

\section{ABSTRACT}

Objectives: Persons with disabilities, especially those with a severe disability, have a vague anxiety about future disasters; however, the measures of selfassistance for disaster preparedness have not been standardised. The present study aimed to describe disaster-related anxiety and behaviours related to disaster preparedness among persons who have cervical cord injury in Japan.

Design: Qualitative study.

Setting: Tokyo Metropolitan area, Japan.

Participants: 16 persons with cervical cord injury participated. Inclusion criteria were being 20 years old and older, being diagnosed with cervical cord injury, being able to communicate verbally, having an interest in disaster preparedness, and belonging to a self-help group of persons with cervical cord injury in the Tokyo Metropolitan area.

Results: Participants usually had 'anxiety about health management' and it became more serious once they thought about a disaster. We identified three themes in relation to their anxiety: 'storing needed items,' 'staying in a safe place' and 'having reliable caregivers.' We also identified three other themes that were the reasons behind these themes: 'travel experiences,' 'experiences of failure' and 'information from peers.'

Conclusions: To buffer the anxiety about health management in a disaster, it would be important for persons with cervical cord injury to store needed items, stay in a safe place and have reliable caregivers. Various daily experiences, including experiences of failure, would encourage such behaviours.

\section{INTRODUCTION}

${ }^{1}$ Department of Social Rehabilitation, Research Institute, National Rehabilitation Center for Persons with Disabilities, Saitama, Japan

${ }^{2}$ Institute of Gerontology, The University of Tokyo, Tokyo, Japan

Correspondence to Dr Kyo Takahashi; tkyo-tky@umin.ac.jp
In a disaster, persons with disabilities are prone to various problems associated with health maintenance that are generally not encountered by their able-bodied counterparts. ${ }^{12}$ Article 11 of the UN Convention of the Rights of Persons with Disabilities states the need for the protection and safety of persons with disabilities in situations of risk, including disasters. ${ }^{3}$ However, it is not realistic for persons with disabilities to simply wait for emergency services in a mega disaster

\section{Strengths and limitations of this study}

- This study targeted persons with a severe disability who can be most vulnerable in a disaster situation.

- The use of qualitative methods enabled the researchers to illustrate the anxiety that stems from disasters and the self-assistance behaviours among participants

- This study only included participants with a high interest in disaster preparedness.

- Triangulations with other populations were not performed.

that paralyses all infrastructure. As with other populations, persons with disabilities need to prepare themselves to manage their own health condition in a disaster. ${ }^{4}$ In the Sendai Framework for Disaster Risk Reduction 2015-2030, persons with disabilities are expected to take an active role in all processes of disaster preparedness, recovery, rehabilitation and reconstruction. ${ }^{5}$ The US National Organization on Disability encourages self-assistance by suggesting that persons with disabilities have an emergency plan that includes four components: personal network, escape, information and essential items. ${ }^{6}$ In particular, for those with a severe disability, such as cervical cord injury (CCI), their preparedness in the event of a disaster is vital. For example, the lack of a clean catheter could result in a urinary tract infection for those requiring clean intermittent catheterisation. ${ }^{7}{ }^{8}$ Moreover, if they are forced to stay in an unfamiliar environment, such as an evacuation shelter, even for a short time, the risk of pressure sores is likely to increase. ${ }^{89}$

Disaster preparedness, which involves forecasting and taking precautionary measures prior to an imminent threat when advance warnings are possible, ${ }^{10}$ for persons with disabilities has been investigated mainly in the context of risk and support. A US nationwide 
survey identified physical disability itself as a predictor of worse preparedness among 1304 older adults. ${ }^{11}$ Some researchers focused on the importance of support for children with disabilities. ${ }^{12-14}$ Tanaka, a Japanese paediatrician, emphasised the need for inclusion of children with disabilities in their local community for disaster preparedness based on his experience in the Great East Japan Earthquake. ${ }^{12}$ Baker and colleagues conducted a study involving educational intervention among 121 families of children with disabilities, and confirmed its effectiveness for family preparedness against disasters, such as having a written family emergency plan. $^{13}$ Compared with the above research, studies on the self-assistance of persons with disabilities have been limited, especially among persons with a severe disability. A US study targeting full-time wheelchair users with spinal cord injury compared their confidence with evacuation to actually having an evacuation plan. ${ }^{15}$ This study showed the gap between confidence and actual behaviours regarding disaster preparedness; however, it did not explore the participants' deep feelings about taking adequate measures of preparedness for disasters.

Japan experienced an unprecedented catastrophe on 11 March 2011: The Great East Japan Earthquake, which was a massive earthquake, accompanied by numerous foreshocks and hundreds of aftershocks that hit the northeastern regions of Japan, resulted in tsunamis that severely damaged the coastal areas. This natural disaster also triggered the Fukushima Daiichi Nuclear Power Plant accidents. The Japan National Police Agency reports that more than 15000 people were killed by these disasters. ${ }^{16}$ Approximately 5 years have passed; however, numerous victims are still suffering health problems caused by the disaster. ${ }^{17} 18$ Even in the Tokyo Metropolitan area, persons with disabilities, especially those with a severe disability, have a vague anxiety about future disasters; however, the measures of self-assistance for disaster preparedness have not been standardised. ${ }^{19}$ In other words, the anxiety of persons with a severe disability and their particular needs are distinct from other vulnerable populations' needs, and these are not sufficiently understood by their community, caregivers or even the individuals themselves. To substantially decrease the risk of mortality for disaster victims, their particular needs should be clarified and appropriate disaster preparedness training conducted.

Persons with disability, especially those with a severe disability, are one of the most vulnerable populations during and after a disaster. For example, persons with CCI can be most vulnerable in terms of immobility due to their dependency on environmental factors, such as physical environment, electricity and human resources. This study aimed to describe the anxious feelings about future disasters and self-assistance of disaster preparedness among persons with CCI in Japan. We targeted persons with CCI in self-help groups in the Tokyo Metropolitan area who experienced the Great East
Japan Earthquake. To focus on the particular feelings and self-assistance behaviours of persons with CCI, we used qualitative methods that enabled us to analyse their actual voices inductively.

\section{METHODS}

\section{Participants}

The inclusion criteria for this study were being 20 years old and older, being diagnosed with CCI, being able to communicate verbally, having an interest in disaster preparedness and belonging to a self-help group of persons who have CCI in the Tokyo Metropolitan area. The first author asked the president of a self-help group in Tokyo to participate in this study. Then the president asked 14 core members if they agreed to be contacted by the first author. After obtaining their approval, the president provided their email addresses to the first author. Using that information, the first author sent an email to 14 potential candidates and asked about their participation. Among the 14 members, we could not recruit two members as they were busy. During the interviews with the 12 participants, the first author asked them to introduce other possible participants in the same way as they were contacted. One participant introduced the president of a self-help group in Kanagawa Prefecture (a neighbouring prefecture to Tokyo). The president of the Kanagawa group introduced two members. In total, we recruited 16 persons with CCI as participants (1 president and 12 members in Tokyo; 1 president and 2 members in Kanagawa).

\section{Data collection}

From June to August 2014, the first author conducted the semi-structured interviews with each participant at the participant's home or a place of their choosing. Some participants had a personal assistant or a family member attend with them. Interview times varied from 90 to $360 \mathrm{~min}$. Before conducting the interviews, we developed an interview guide based on the discussions between the authors, previous work and literature reviews, and pretested it among persons with CCI. Using the interview guide, the first author asked open-ended questions regarding socioeconomic status (age, sex, living status), disability (timing, severity, activities of daily living, present illness, complications, devices, medicines and care services), disaster preparedness (previous experiences, items, evacuation plans, information and contact measures), social participation (belonging groups, community activity and job), human resources (family, friends, caregivers and medical staff) and social capital (community trust, sense of belonging and community resources for a future disaster). The participants' interviews were audio recorded, and the first author created field notes and verbatim transcripts from which the analysis was conducted.

\section{Data analysis}

Verbatim transcripts were inductively analysed using thematic analysis. ${ }^{2021}$ Thematic analysis is one of the most 
optimal inductive methodologies to organise the qualitative data in an intelligible manner. The first and second authors familiarised themselves with the verbatim transcripts by reading them repeatedly. Then the first author coded the salient narratives and initially grouped them according to their characteristics. In particular, the first author initially focused on the participants' anxious feelings about future disasters and subsequently extracted behaviours of disaster preparedness. After ongoing discussions between both authors, the first author developed several themes as well as a conceptual model showing the hypothetical interactions among developed themes using NVivo 10 (QSR International Pty Ltd, Victoria). To overcome the validity threats, ${ }^{22}$ the first author discussed the results of the analysis with a working group for toileting issues at the National Rehabilitation Center for Persons with Disabilities in Japan. Additionally, as a member validation, ${ }^{23}$ the first author sent the results of the analysis to all participants and received comments from six of them. After revising the result of the initial analysis, the authors developed the definite themes, which reflected the participants' anxiety, preformed preparation behaviours and related factors.

\section{RESULTS}

Among the 16 participants, 14 were male, 9 lived alone and 7 were employed (Mean age: 48.3 years). Regarding disability, all participants were dependent for basic activities of daily living, 13 had CCI for over 20 years and 15 used an electric wheelchair when leaving their homes. Regarding continence, 12 used an indwelling catheter and 15 used disimpaction services. Caregivers for bowel control varied; they included visiting nurses, visiting helpers and family members.

\section{Anxiety about managing health in a disaster}

Our participants were anxious about inconvenient daily life after a disaster rather than survival during a disaster. Many participants disclosed that they would reconcile themselves to a mega disaster, which damages lifelines, for their survival. However, all participants strongly expressed a primary concern of anxiety about managing their health conditions. In particular, participants felt anxious about urinary and faecal control, pressure sores and body temperature control. Once they thought about a disaster, such anxiety seemed to worsen.

Of course, I always have a fear of fecal incontinence because I have CCI. When I am out (in a disaster), it becomes much bigger. About urine-sometimes it doesn't flow smoothly because the drain is stopped up. I have had an experience of being transferred by ambulance because of that. So, I always have such anxiety.

Some participants expressed particular anxiety about controlling their body temperature when the electricity was down. A participant was afraid of having hyperthermia or hypothermia without an air conditioner.

You know, because we (persons who have CCI) cannot control our body temperature by ourselves, we use an electric air conditioner. It'll be a real problem if the electricity is out (due to a disaster). Especially in summer, also in winter, it's really going to be a vital question for us.

\section{Measures of disaster preparedness}

Our participants had various measures of disaster preparedness; these themes were 'storing needed items,' 'staying in a safe place' and 'having reliable caregivers.'

\section{Storing needed items}

Most participants stored needed items to manage their health condition in case of disaster. In addition to essential items, such as food, water and information devices, the items to manage their health condition were well prepared. For example, cathartic medicines and particular devices for defecation were stored by those needing disimpaction services. In addition to the items for themselves, some participants stored essential items for their caregivers. A participant stored needed items, such as bottled water, food and medicines, for himself and for his accompanying caregiver.

I prepare things because I don't want to have a hard time in case I survive a disaster. I won't know until then whether my caregiver can stay with me in such a situation. It really depends on the situation at that time. Even if my caregiver can be with me, it will be very hard if I don't have enough medical stuff like drugs ... If I'm all alone, I could resign myself. But, basically, I'm with my caregiver. I have to think of that. I cannot survive by myself. So, I need a caregiver to survive.

\section{Staying in a safe place}

All participants were unwilling to go to an evacuation shelter because they were not sure if the shelter would be accessible. They understood that they could not manage their health in an unusual environment. Many of them even did not know where the public evacuation shelter was in their community. Rather than seeking a place for non-disabled people, they preferred to stay at home where they could feel safe. A participant cared about his relationship with his neighbours because he believed that neighbours' support would be necessary if he stayed at home in a disaster. He said,

You know, we (persons who have CCI) basically shouldn't go out (in a disaster). When an earthquake with a seismic intensity of 6 or 7 occurs, we should be at home as long as our houses aren't destroyed. It'll be better to wait for supporters here rather than going out (to an evacuation shelter).

Although staying at home was the first choice, some participants believed in going to another place if a 
disaster had severely damaged the basic infrastructure. A participant developed an evacuation plan after the Great East Japan Earthquake. He had several places to evacuate to with his family, such as his parents' house, wife's parents' house and accessible hotels where he and his family had stayed before.

After that (the Great East Japan Earthquake), I discussed with my wife and we agreed to evacuate to a safe place away from here if a disaster occurs. Rather than staying near here, it'll be better to drive to a rural, non-affected area where we can live.

\section{Having reliable caregivers}

Even if persons who have CCI store needed items and stay in a safe place, it is impossible for them to survive without reliable caregivers. Nine participants living independently emphasised the importance of caregivers, even in normal circumstances. Although the participants actively used caregivers for their independent living, they actually realised that they are physically dependent on caregivers.

I cannot go to bed without a human helping me. I cannot eat anything if nobody prepares food. And, I cannot dump my pee by myself. That's what I'm saying. If someone helps me, I could do anything by myself. So, a person who helps me is the most important.

Despite its importance, whether they can be with a caregiver in a disaster depends on their personal relationship with that caregiver. Those who have a good personal relationship with their caregivers seemed confident that their caregivers would continue to supply aid during a disaster. In contrast, those without such relationships were anxious about health management in a disaster. A participant, who used a caregiver service for $20 \mathrm{~h}$ a day, was fortunately able to stay with a caregiver in the aftermath of the Great East Japan Earthquake.

On that day (of the Great East Japan Earthquake), one of my caregivers was training in a gym near here, and he came to see me. The caregiver who was supposed to come on that day couldn't come due to the traffic panic. So, I asked him to stay with me until the next morning.

\section{Travel experiences, experiences of failure and information from peers}

Aside from the above three themes, we found three other themes: 'travel experiences,' 'experiences of failure' and 'information from peers.' 'Travel experiences' seemed to be related to 'storing needed items' and 'staying in a safe place.' Some participants who often travelled were good at selecting needed items and finding a safe place, such as their favourite accessible hotels. Another theme was 'experience of failure.' Although 'experience of failure,' such as incontinence, could increase anxiety about their health condition, it might encourage disaster preparedness actions, including 'storing needed items' in case of a similar situation. Similarly, the participants could realise the importance of disaster preparedness by receiving 'information from peers' about individual experiences of disaster, which can be frightening to them. A participant had an opportunity to see persons with disabilities who survived the Great East Japan Earthquake. She expressed the impact of listening to peers' stories.

\begin{abstract}
Maybe this is because I have a disability. If a person using wheelchair, a person with a disability like me, says something, I would listen to that advice. Even though I don't have any experience or never imagined it, when I listen to the difficult experiences in a disaster from a person like me, I could imagine the same situation happening to me.
\end{abstract}

\section{DISCUSSION}

We found that bodily maintenance was a chief anxiety among persons who have CCI when they thought about what to do in a disaster. This result is similar to a that in a previous study that qualitatively analysed the voices of parents of children with a severe disability. Yamamoto and colleagues described various difficulties in managing health in a disaster, such as the difficulty in controlling body temperature. ${ }^{19}$ Although the participants' conditions are distinct from those in our study, this similar result implies the universal importance and difficulty in managing health in a disaster among persons with a severe disability. In addition to body temperature control, our study found urinary and faecal control to be particular anxieties in a disaster. This difference could be explained by the particular conditions of CCI. ${ }^{24}{ }^{25}$ As expressed by our participants, it is difficult to erase anxiety about disasters since they are related to their usual anxiety about their body conditions. However, it might be possible to undertake measures to alleviate such anxiety.

Our study found three measures of disaster preparedness. First, storing needed items would be useful. Persons who have CCI need to store necessary items for bodily maintenance, in addition to the essential items recommended by the US National Center on Disability. ${ }^{6}$ For example, those needing urinary bladder irrigation require sufficient clean water and adequate devices. ${ }^{26}$ Having sufficient nutrition is also essential to prevent pressure sores, ${ }^{27}$ and a blanket helps to prevent hypothermia even without electricity. ${ }^{28}$ Thus, storing difficult-to-obtain items that are nonetheless needed, as well as essential items, would be useful for managing health in a disaster. Moreover, our study uniquely illustrated the importance of storing needed items for caregivers. As a participant mentioned, persons with CCI could not survive without a caregiver in a disaster. Supporting the life of caregivers by storing needed items is as essential for those with CCI as storing items is necessary for saving their own lives. Thus, it would be also useful for persons with CCI to create a list of 
needed items, store them and watch the expiration dates of these items.

Second, staying in a safe place is also essential. It is well known that a disaster damages the surrounding physical environment and negatively affects people's mental health. ${ }^{17} 29$ Thus, it is essential for people's mental health to stay in a safe environment. For persons who have CCI, creating a safe environment is more challenging. ${ }^{30}$ They need to have a private space for urination and defecation, a bed to prevent pressure sores and a room with an air conditioning system for body temperature control. Our study differentiates two possible safe places for individuals with CCI to stay-either at home or somewhere away from home. In the event that they stay at home, it is important to take measures to ensure survival within the home environment without electricity, such as being able to charge electric devices beforehand and running the air conditioning system off a battery or generator. Having a good relationship with neighbours would also be a useful support strategy in a disaster. ${ }^{31}$ Our study results also suggest that having alternative safe places would help manage health in a disaster. It is important to ensure the availability of safe transportation methods to such places, as it would be riskier than it would be to stay at home if individuals with CCI cannot reach their chosen safe place because of a lack of preparation and experience. Periodically practising an evacuation route should be encouraged so that individuals can familiarise themselves and their caregivers with the transportation methods to their chosen evacuation place in a disaster. Moreover, evacuation shelter planners should ensure accessibility and reasonable accommodation for evacuees with a severe disability, such as CCI. ${ }^{32}$

Third, having reliable paid caregivers is vital. As many participants mentioned, persons who have CCI cannot live independently without caregivers who support their activities of daily living. ${ }^{33}$ However, in reality, whether a paid caregiver can support a person who has CCI in a disaster depends on the personal relationship. Although many of our participants seemed to have good personal relationships with their paid caregivers, ethically, providing support in a disaster should not depend on the strength of the personal relationship because caregivers must protect themselves first. To ensure a stable supply of paid caregivers, persons who have CCI would need to have multiple caregiver sources, several methods of contacting caregivers and the ability to contact neighbours as emergency caregivers. Paid caregivers would also need to make efforts to develop a support system in a disaster at the personal, family and workplace levels.

In addition to the above findings, the results indicated the importance of previous negative experiences of disaster preparedness among persons who have CCI. For example, incontinence is unwelcome in daily life and can cause severe anxiety in a disaster. However, with that negative experience, persons who have CCI could become more careful about their urinary and faecal control, thereby resulting in better disaster preparedness. Experiences of overcoming a stressful life event could make people more resilient to other stressful life events. ${ }^{34}$ Although experiences of failure are usually perceived as negative, it might be important for persons who have CCI to regard it as an opportunity to improve their disaster preparedness. Similarly, experience in listening to the survival stories of peers could frighten persons who have CCI. However, it could also encourage disaster preparedness in them by allowing them to imitate peers' successful behaviours. Peer counselling is a major component in realising independent living among persons with disabilities. ${ }^{35}$ It might also be key to promoting disaster preparedness among those with disabilities. Finally, travel experiences could also encourage disaster preparedness among persons who have CCI. Unlike experiences of failure and information from peers, travelling does not cause anxiety in a disaster. By travelling, skills for selecting needed items and staying in a safe place increase. Additionally, the experience of being with a caregiver in an unusual environment would be useful in a disaster. Thus, it is recommended that persons who have CCI experience various forms of travelling to encourage disaster preparedness.

This study has some limitations. First, we only recruited persons with CCI who had a high interest in disaster preparedness. Although we were able to develop the themes related to buffering against anxiety by targeting this population, the result would be a little different if we included those without any interest in disaster preparedness. Regarding negative cases, persons who have CCI but do not have any interest in disaster preparedness should be also targeted in a further study. While we targeted one of the largest self-help groups for persons with CCI in the Tokyo Metropolitan area to obtain the qualitative data, the study results should be generalised carefully as the sampling and analysis procedures were not conducted in an epidemiological manner and most persons with CCI do not belong to such groups. Another limitation was regarding our methodology for considering disaster preparedness. We inductively developed the themes of disaster preparedness based on the direct experiences of persons who have CCI; however, another effective measure of disaster preparedness could be proposed by other populations, such as experts in disaster preparedness. For example, we did not identify the importance of the surrounding community, yet this has been confirmed among those without disabilities. $^{36} 37$ Triangulation should be performed and include the opinions and experiences of various populations, such as experts, caregivers and public officials.

\section{CONCLUSIONS}

Despite the above limitations, we have nonetheless described the anxiety that stems from disasters and the ways of managing such anxiety-namely, behaviours related to disaster preparedness-among persons who 
have CCI. In particular, to alleviate anxiety about health management in a disaster, such as urinary and faecal control, it would be useful for persons who have CCI to store needed items, stay in a safe place and have reliable caregivers. Additionally, various experiences, including experiences of failure, could encourage such behaviours. Our findings could be useful in designing an effective intervention to encourage self-assistance in disaster preparedness among persons who have CCI.

Acknowledgements The authors are deeply thankful to the participants who kindly cooperated in this study. The authors also thank Dr. Jun Suzurikawa and the members of the working group on toileting issues at the National Rehabilitation Center for Persons with Disabilities for their generous feedback regarding the results of our analysis.

Contributors KT and YK were involved in the study concept and design. KT was involved in the participant recruitment. KT and YK were involved in the data analysis and interpretation. KT and YK were involved in the manuscript preparation.

Funding This work was supported by a Japan Society for the Promotion of Science (JSPS) KAKENHI Grant-in-Aid for Young Scientists (B) (Grant number: 26870861)

Competing interests None declared.

Ethics approval The Ethics Committee of the National Rehabilitation Center for Persons with Disabilities approved this study (C26053). All participants made their decisions regarding participation after being asked by the president of the self-help groups to which they belonged. After verbally assuring their voluntary participation and confidentiality, we obtained written consent from all participants. For those who could not write with a pen, we asked their caregivers to sign the consent form on their behalf.

Provenance and peer review Not commissioned; externally peer reviewed.

Data sharing statement No additional data are available.

Open Access This is an Open Access article distributed in accordance with the Creative Commons Attribution Non Commercial (CC BY-NC 4.0) license, which permits others to distribute, remix, adapt, build upon this work noncommercially, and license their derivative works on different terms, provided the original work is properly cited and the use is non-commercial. See: http:// creativecommons.org/licenses/by-nc/4.0/

\section{REFERENCES}

1. Mitchell D, Karr V, eds. Crises, conflict and disability: ensuring equality. New York: Routledge, 2014.

2. World Health Organization, The World Bank. World report on disability. Geneva: WHO, 2011.

3. United Nations. Convention on the rights of persons with disabilities. http://www.un.org/disabilities/convention/conventionfull.shtml (accessed 3 Sep 2015).

4. Burns AS, O'Connell C, Rathore F. Meeting the challenges of spinal cord injury care following sudden onset disaster: lessons learned. $J$ Rehabil Med 2012;44:414-20.

5. The United Nations Office for Disaster Risk Reduction. Sendai framework for disaster risk reduction 2015-2030. http://www.unisdr. org/we/inform/publications/43291 (accessed 4 Nov 2015)

6. Morris JT, Jones ML. Emergency preparedness for people with disabilities: guide and checklist. Arch Phys Med Rehabil 2013;94:219-20.

7. Luo DY, Ding MF, He CQ, et al. Bladder management of patients with spinal cord injuries sustained in the 2008 Wenchuan earthquake. Kaohsiung J Med Sci 2012;28:613-18.

8. Rathore MF, Rashid P, Butt AW, et al. Epidemiology of spinal cord injuries in the 2005 Pakistan earthquake. Spinal Cord 2007;45:658-63.

9. Sato T, Ichioka S. Pressure ulcer occurrence following the Great East Japan Earthquake: observations from a disaster medical assistance team. Ostomy Wound Manage 2012;58:70-5.
10. Kent R. Disaster preparedness. In: United Nations disaster management programme. 2nd edn. Geneva: Department of Humanitarian Affairs, 1994:11.

11. Al-Rousan TM, Rubenstein LM, Wallace RB. Preparedness for natural disasters among older US adults: a nationwide survey. $A m J$ Public Health 2014;104:506-11.

12. Tanaka S. Issues in the support and disaster preparedness of severely disabled children in affected areas. Brain Dev 2013;35:209-13.

13. Baker MD, Baker LR, Flagg LA. Preparing families of children with special health care needs for disasters: an education intervention. Soc Work Health Care 2012;51:417-29.

14. Baker LR, Cormier LA. Disaster preparedness and families of children with special needs: a geographic comparison. J Community Health 2013;38:106-12.

15. McClure LA, Boninger ML, Oyster ML, et al. Emergency evacuation readiness of full-time wheelchair users with spinal cord injury. Arch Phys Med Rehabil 2011;92:491-8.

16. Japan National Police Agency. Countermeasures for the Great East Japan Earthquake 2015. http://www.npa.go.jp/archive/keibi/biki/ index e.htm (accessed 3 Sep 2015)

17. Kako M, Arbon P, Mitani S. Disaster health after the 2011 Great East Japan Earthquake. Prehosp Disaster Med 2014; 29:54-9.

18. Sakai A, Ohira T, Hosoya M, et al. Life as an evacuee after the Fukushima Daiichi nuclear power plant accident is a cause of polycythemia: the Fukushima Health Management Survey. BMC Public Health 2014;14:1318.

19. Yamamoto $M$, Nakagawa K, Ishigami $Y$, et al. Difficulties and worries of the life to sruvive in a disaster: characteristics of the experiences in the Great East Japan Earthquake to severe mental and physical disabled people who live in the capital region. Shouni Hoken Kenkyu 2013;72:298-304

20. Braun V, Clarke V. Using thematic analysis in psychology. Qual Res Psychol 2006;3:77-101.

21. Guest G, MacQueen KM, Namey EE. Applied thematic analysis. Thousand Oaks: Sage Publications, 2012

22. Maxwell J. Qualitative research design: an interactive approach. 3rd edn. Thousand Oaks: Sage Publications, 2013.

23. Seale C. The quality of qualitative research. London, California, New Delhi: Sage Publications, 1999.

24. Alpert MJ, Wisnia S. Spinal cord injury and the family: a new guide. Cambridge: Harvard University Press, 2008.

25. Palmer S, Kriegsman KH, Palmer JB. Spinal cord injury. 2nd edn. Baltimore: The Johns Hopkins University Press, 2008.

26. Gates A. The benefits of irrigation in catheter care. Prof Nurse 2000;16:835-8.

27. Thomas DR. Role of nutrition in the treatment and prevention of pressure ulcers. Nutr Clin Pract 2014;29:466-72.

28. Furukawa $\mathrm{H}$, Kudo $\mathrm{D}$, Nakagawa $\mathrm{A}$, et al. Hypothermia in victims of the Great East Japan Earthquake: a survey in Miyagi prefecture. Disaster Med Public Health Prep 2014;8:379-89.

29. Yabe H, Suzuki Y, Mashiko $\mathrm{H}$, et al. Psychological distress after the Great East Japan Earthquake and Fukushima Daiichi Nuclear Power Plant accident: results of a mental health and lifestyle survey through the Fukushima Health Management Survey in FY2011 and FY2012. Fukushima J Med Sci 2014;60:57-67.

30. Richards JS, Bombardier CH, Tate D, et al. Access to the environment and life satisfaction after spinal cord injury. Arch Phys Med Rehabil 1999;80:1501-6.

31. Phibbs S, Good G, Severinsen C, et al. What about us? Reported experiences of disabled people related to the Christchurch earthquakes. Procedia Econ Finan 2014;18:190-7.

32. US Federal Emergency Management Agency. Guidance on planning for integration of functional needs support services in general population shelters. 2010. http://www.fema.gov/pdf/about/odic/fnss guidance.pdf (accessed 3 Sep 2015).

33. Ide-Okochi A, Tadaka E, Fujimura K. The meaning of self-care in persons with cervical spinal cord injury in Japan: a qualitative study. BMC Neurol 2013;13:115.

34. Antonovsky A. Unraveling the mystery of health: how people manage stress and stay well. San Francisco: Jossey-Bass Publishers, 1987

35. Fuhrer MJ, Rossi LD, Gerken L, et al. Relationships between independent living centers and medical rehabilitation programs. Arch Phys Med Rehabil 1990;71:519-22.

36. Aldrich D. Building resilience: social capital in post-disaster recovery Chicago: The University of Chicago Press, 2012.

37. Reininger BM, Rahbar $\mathrm{MH}$, Lee M, et al. Social capital and disaster preparedness among low income Mexican Americans in a disaster prone area. Soc Sci Med 2013;83:50-60. 